\title{
Nasrin Sotoudeh, un proceso arbitrario. Videoconferencia Las mujeres activistas iraníes y la justicia
}

\section{Nasrin Sotoudeh, an Arbitrary Process. Videoconference: Iranian Women Activists and Justice}

\author{
Susana Silva \\ Facultad de Ciencias Políticas y Sociales \\ Universidad Nacional Autónoma de México \\ susana.silva@politicas.unam.mx
}

Son las dos de la mañana en la ciudad de Teherán del 26 de abril de 2019; en la Ciudad de México son las cuatro de la tarde del 25 de abril. Estamos en La Teatrería, el recinto está completo, las personas que allí se encuentran comparten un interés común: la preocupación por la violación de los derechos humanos que aqueja a la población civil de Irán.

Kaveh Parmas (actor de teatro) toma la batuta, comienza por proyectar un fragmento del largometraje Taxi, de Jafar Panahi un hombre que ha sido privado de sus derechos, pero no por eso limitado de su actividad firme en comunicar el eco y las heridas que han estado presentes durante 40 años ante una revolución de carácter ideológico. La escena es especial; una mujer con un ramo de rosas rojas mira a la cámara para decirnos que la gente del cine es la gente en la que más se puede confiar, para después revelar:

Sabes, Jafar, a veces lo hacen a propósito. Sabemos que estamos siendo observados. Sus tácticas son evidentes: primero construyen un caso político... luego añaden un escándalo sexual. Ellos hacen de tu vida un infierno. Cuando finalmente te dejan en libertad, el mundo aquí se convierte en una prisión aún más grande; hacen de tus amigos tus peores enemigos. Queda huir del país o empezar a rezar para volver a la cárcel. 
Cinco mujeres, cinco actrices, pasan individualmente al escenario de la sala B de La Teatrería para leer unos cuantos poemas de algunos representantes de la literatura iraní: Fernanda Borches, Sophie Alexander, Gabriela de la Garza, Diana Bracho y Concepción Márquez dan voz a los pensamientos de Forugh Farojzad, Ahmad Shamlú y Mehdi Akhavan-Sales, que aspiran a una libertad imposible de conseguir ante una ferviente represión, pero sin impedimento para soñar con su posible llegada.

Aquella mujer con el ramo de rosas es Nasrin Sotoudeh, abogada iraní defensora de las mujeres y los derechos humanos de su país. El pasado 12 de marzo fue condenada a prisión en Teherán; ha sido sentenciada a 38 años de prisión y 148 latigazos por oponerse al uso forzoso del velo o hiyab. Su marido, Reza Khandan, accedió a conceder una videoconferencia para el público de La Teatrería. La traducción quedó a cargo de Shekoufeh Mohammadi Shirmahaleh, investigadora del Instituto de Investigaciones Filológicas de la Universidad Nacional Autónoma de México.

Al entrar en contacto, Reza agradece la preocupación de los presentes y aprovecha la oportunidad para hablar de un asunto que incumbe a todo ser humano: la justicia. En sus palabras, en Irán se ha hecho una violación constante de los derechos humanos de los ciudadanos, en especial los que corresponden a la mujer. La justicia judicial es una lucha incesante para las personas que cumplen con una labor activista porque no se respetan sus garantías judiciales: son torturados y perseguidos. El caso de Nasrin es uno más de los muchos que integran el sistema establecido hace 40 años como resultado de la revolución islámica. La presión internacional es clave para que la justicia pueda tener lugar en los espacios gubernamentales de todos los países del mundo.

La pequeña introducción de Reza dio pie a una serie de preguntas por parte del público. Diana Bracho inició preguntando si existe alguna posibilidad de revertir la sentencia a través del apoyo de organizaciones internacionales, como aquellos que provienen de Francia, Italia, España y Estados Unidos. Khandan dejó claro que la única manera de revertirla sería con acciones ilegales, ya que, en su momento, no se apeló el caso, como protesta hacia los injustos procesos en los tribunales de Irán.

El estado de salud de Nasrin goza de las mejores condiciones espiritualmente, pero no se puede decir lo mismo de su estado físico: la primera vez que fue detenida, en 2010, hizo una huelga de hambre de 49 días; en 
el actual encarcelamiento ya ha realizado dos huelgas más, una de $30 \mathrm{y}$ otra de 27 días. Tiene autorización para hablar por teléfono dos veces a la semana por uno o dos minutos y puede ser visitada solamente una vez a la semana. En ocasiones, se le ha prohibido la comunicación con su familia sin explicación alguna. Tiene negado el envío de escritos; esto no quiere decir que no puedan ser remitidos secretamente.

Reza comentó que en una de sus detenciones -en la que fue condenado a seis años de prisión por poseer en su hogar botones con la consigna "Yo estoy en contra del velo obligatorio" - pudo obtener información sobre el estado de su esposa, en ese periodo también encarcelada, por las visitas que sus hijos les hacían a ambos. Esta vez, Nasrin no está en la zona de alta seguridad - como fue durante ocho meses, en su primer arresto por el Ministerio de Inteligencia Iraní-. Ahora se encuentra en la prisión de Evín, compartiendo celda con otras 23 mujeres acusadas de espionaje, que en realidad están procesadas con expedientes falsos.

"La República Islámica es un gobierno basado en la ideología islámica. El velo es un lema que la autoridad ha tenido desde la revolución; es uno de los pilares de la ideología. Ellos creen que si este tipo de con- signas cae, caerá todo el sistema", comentó Reza. Por eso, negarse a usar el velo "lo consideran como una amenaza; resulta algo usado de forma subversiva. Al inicio de la revolución, los hombres tenían que portar un código de vestimenta; esto ha cambiado; ahora las únicas obligadas son las mujeres. El velo es una bandera islámica; por eso se tiene la presencia de la policía moral”, agregó.

Reza Khandan finalizó con un agradecimiento a todos los que integraron el evento y manifestó sus mejores deseos para que México también reciba justicia en los casos de feminicidio. El público de La Teatrería concluyó con un fraternal aplauso para Nasrin y su marido, y dio muestras de un apoyo que termina por superar las barreras que existen entre un país y otro. ¿Qué es lo último que queda por hacer para mostrar ese apoyo a Nasrin Sotoudeh? Unirse a las campañas de artistas y abogados que están circulando en internet. Desde México, mandar cartas o peticiones a la embajada de Irán.

\section{Susana Silva}

Estudiante de la carrera de Ciencias de la Comunicación en la Facultad de Ciencias Políticas y Sociales de la UNAM. Redactora y colaboradora de la sección de cine de la revista digital Pórtico MX. 